\title{
Cadmium Sulfide Thin Films Deposited onto MWCNT/Polysulfone Substrates by Chemical Bath Deposition
}

\author{
M. Moreno, ${ }^{1}$ G. M. Alonzo-Medina, ${ }^{1}$ A. I. Oliva, ${ }^{2}$ and A. I. Oliva-Avilés ${ }^{1}$ \\ ${ }^{1}$ División de Ingeniería y Ciencias Exactas, Universidad Anáhuac Mayab, Carretera Mérida-Progreso Km. 15.5 AP 96 Cordemex, \\ 97310 Mérida, YUC, Mexico \\ ${ }^{2}$ Centro de Investigación y de Estudios Avanzados del IPN, Unidad Mérida, Departamento de Física Aplicada, AP 73 Cordemex, \\ 97310 Mérida, YUC, Mexico
}

Correspondence should be addressed to A. I. Oliva-Avilés; andres.oliva@anahuac.mx

Received 22 February 2016; Revised 29 June 2016; Accepted 11 July 2016

Academic Editor: Kaveh Edalati

Copyright (C) 2016 M. Moreno et al. This is an open access article distributed under the Creative Commons Attribution License, which permits unrestricted use, distribution, and reproduction in any medium, provided the original work is properly cited.

Cadmium sulfide (CdS) thin films were deposited by chemical bath deposition (CBD) onto polymeric composites with electric field-aligned multiwall carbon nanotubes (MWCNTs). MWCNT/polysulfone composites were prepared by dispersing low concentrations of MWCNTs within dissolved polysulfone (PSF). An alternating current electric field was "in situ" applied to align the MWCNTs within the dissolved polymer along the field direction until the solvent was evaporated. $80 \mu \mathrm{m}$ thick solid MWCNT/PSF composites with an electrical conductivity 13 orders of magnitude higher than the conductivity of the neat PSF were obtained. The MWCNT/PSF composites were subsequently used as flexible substrates for the deposition of CdS thin films by CBD. Transparent and adherent CdS thin films with an average thickness of $475 \mathrm{~nm}$ were obtained. The values of the energy band gap, average grain size, rms roughness, crystalline structure, and preferential orientation of the CdS films deposited onto the polymeric substrate were very similar to the corresponding values of the CdS deposited onto glass (conventional substrate). These results show that the MWCNT/PSF composites with electric field-tailored MWCNTs represent a suitable option to be used as flexible conducting substrate for CdS thin films, which represents an important step towards the developing of flexible systems for photovoltaic applications.

\section{Introduction}

Cadmium sulfide (CdS) has been widely and successfully used as a window layer for optical and photovoltaic applications [1-3]. CdS grows naturally as n-type semiconductor with an energy band gap of $2.42 \mathrm{eV}$ at room temperature [4], resulting in a desirable material for solar applications due to its optical and electrical properties. For solar cell applications, $\mathrm{CdS}$ thin films have been used as a window material together with several semiconductors such as $\mathrm{CdTe}, \mathrm{Cu}_{2} \mathrm{~S}, \mathrm{CuInSe}_{2}$, InP, and $\mathrm{Cu}(\mathrm{In}, \mathrm{Ga}) \mathrm{Se}_{2}$, and solar cell efficiencies between $14 \%$ and $19 \%$ have been reported [5-10]. Several techniques have been extensively used to prepare CdS in a thin film configuration onto different substrates, such as electrodeposition [11], chemical bath deposition [12], spray deposition [13], femtosecond pulsed laser deposition [14], molecular beam epitaxy [15], successive ionic layer adsorption and reaction
[16], screen printing [17], close spaced sublimation [18], RF sputtering [19], metal organic chemical vapor deposition [20], pulsed laser deposition [21], and physical vapor deposition [22], among the most relevant ones. Among these methods, the chemical bath deposition (CBD) has been demonstrated to be a suitable technique to deposit CdS thin films for large area industrial processes [23, 24]. CBD is a simple and low cost technique which does not require high vacuum conditions and, since it is a low-temperature technique $\left(<90^{\circ} \mathrm{C}\right)$, does not limit the choice of the substrate material. It is well known that the physical and chemical properties of semiconducting thin films are highly dependent on the early stages of growth. In the same level of importance, the choice of the substrate also defines the film quality and properties. In the field of II-VI compound semiconductor deposition, Pyrex $^{\oplus}$ [25], glass [26], quartz [14], and silicon [27, 28] are 
among the most used materials due to their availability, costeffectiveness, and inert character. Such substrates do not react with the deposited semiconductors and the surface promotes the formation of optically smooth thin films [29]. Despite the important results and presence of the semiconducting thin films deposited onto the mentioned substrates, their weight, rigidity, and fragility are the main drawbacks for more versatile and far-reaching applications in several technological fields. As an example, one of the major obstacles in the development of low cost and high efficiency solar cells is the use of glass substrates. Ordinary glass substrates have a poor thermal conductivity, making it extremely difficult to maintain a constant annealing temperature across a large area panel and to avoid thermal stresses which may cause breakage during the fabrication [30]. As a response for the mentioned challenges, the usage of flexible substrates, mainly based on polymers and metal foils, has emerged as a convenient option to deposit semiconducting thin films, offering several advantages for many technological and scientific applications [4, 29-35]. In particular, the growth of CdS onto different polymers such as polyethylene terephthalate [4, 3235], flexible polymer-based plastic [29], polyimide [31], and polycarbonate [32-34] has been reported and the resulting films exhibit adequate physical properties, similar to those of the CdS films deposited onto glass. In the configuration of a thin film-based solar cell, the electrical characteristics of the substrate are of paramount importance. For insulating substrates (such as glass) a transparent conducting layer is generally deposited onto the surface of the substrate in order to generate an electrode that, together with the back conducting contact, closes up the "electrical circuit" across the solar cell allowing the usage of the induced photovoltage. However, the high temperatures required to deposit such conducting layers onto polymeric (flexible) substrates may induce damage and/or melting of the substrates as they generally have low glass transition temperatures. In recent years, polymers reinforced with carbon nanotubes (CNTs) have gained attention due to the novel and versatile properties that CNTs offer to the polymeric matrix [36-38]. It has been extensively reported that CNTs importantly modify the physical properties of the polymers when the CNTs are incorporated into the matrix to conform the polymer composites. Electrical, mechanical, and thermal properties of the composites are notoriously enhanced due to presence of CNTs, as CNTs partially transfer their physical properties to the polymeric matrix. Regarding the electrical properties, the inclusion of a very low content of CNTs within a polymer matrix $(<1 \mathrm{wt} \%)$ promotes an increase of several orders of magnitude of the electrical conductivity compared to the conductivity of the pure polymer [39-41]. The combination of CNTs with polymers offers an attractive route not only to the development of reinforced polymer films but also to introducing new electronic properties based on morphological and electrical modifications. This represents a very convenient feature in the photovoltaic area, where the flexibility and enhanced electrical properties of the substrates become relevant requirements for an improved performance.

Here we present a study of the optical, morphological, and structural properties of CdS thin films deposited by CBD onto flexible composite substrates. Low concentrations of multiwall carbon nanotubes (MWCNTs) were incorporated into dissolved polysulfone and an alternating current (AC) electric field was "in situ" applied during the fabrication process to align the MWCNTs along the electric field direction. Polysulfone was selected as the (thermoplastic) polymeric matrix due to the combination of several high-performance properties such as high thermal stability, high toughness and strength, good environmental stress cracking resistance, high heat deflection temperature $\left(\sim 174^{\circ} \mathrm{C}\right)$, and high transparency and combustion resistance [42]. These adequate characteristics for solar applications along with the capability of being dissolved in chloroform (solvent used to disperse the MWCNTs) supported the election of the mentioned polymer for this work. Solid MWCNT/PSF composites with an increased electrical conductivity were obtained by the solution casting technique and used as flexible substrates for the CdS deposition. The average values of thickness, energy band gap, grain size, rms roughness, and crystalline structure of the CdS thin films deposited onto the polymeric composites were obtained and compared to the well-known values of CdS deposited onto glass. The aim of this investigation is to demonstrate that it is possible to fabricate CdS thin films onto a CNT-based polymeric substrate by the CBD technique. The capability to deposit CdS thin films with adequate optical, morphological, and structural properties onto a flexible and electrically enhanced composite represents an important step towards the development of flexible materials for photovoltaic applications.

\section{Materials and Methods}

2.1. Fabrication and Electrical Characterization of MWCNT/ Polysulfone Composite Substrates. MWCNTs grown by chemical vapor deposition ("Baytubes C150P") were supplied by Bayer Material Science [43]. The MWCNTs have inner and outer diameters of approximately $4 \mathrm{~nm}$ and $13 \mathrm{~nm}$, respectively, and length in the range of $1-4 \mu \mathrm{m}$, yielding a distribution of CNT aspect ratio ranging from 80 to 300 [44]. The polymer matrix used in this work was polysulfone (PSF, “UDEL P1700") supplied by Solvay Advanced Polymers [42]. PSF is an engineering thermoplastic with high thermal stability, transparency, and low moisture absorption characteristics among the most relevant characteristics. MWCNT/PSF composite films were fabricated by solution casting using 0.5 weight percent ( $w t \%)$. To fabricate the composite films, $2.5 \mathrm{mg}$ of MWCNTs was dispersed in chloroform $\left(\mathrm{CHCl}_{3}\right)$ using an ultrasonic bath (Cole-Parmer 08895-59, $40 \mathrm{kHz}$ ) for $120 \mathrm{~min}$ (Figure 1(a)). In a parallel process, $500 \mathrm{mg}$ of PSF pellets was dissolved in $2 \mathrm{~mL}$ of $\mathrm{CHCl}_{3}$ forming a viscous PSF/ $\mathrm{CHCl}_{3}$ solution (Figure $1(\mathrm{~b})$ ). The $\mathrm{PSF} / \mathrm{CHCl}_{3}$ and $\mathrm{MWCNT} / \mathrm{CHCl}_{3}$ solutions were then mixed in a common beaker for $15 \mathrm{~min}$ (Figure 1(c)) and the $\mathrm{MWCNT} / \mathrm{PSF} / \mathrm{CHCl}_{3}$ final solution was cast onto a custom-made glass mold with aluminum electrodes for the application of an AC electric field (Figure 1(d)).

The AC voltage applied to the solution was $120 \mathrm{~V}_{\mathrm{rms}}$ at $60 \mathrm{~Hz}$ and the electrode separation was $20 \mathrm{~mm}$, for an electric field of $6 \mathrm{kV}_{\mathrm{rms}} / \mathrm{m}$. After the solution casting, $\mathrm{CHCl}_{3}$ was 


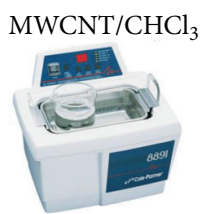

(a)

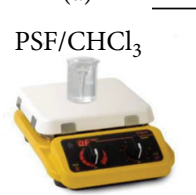

(b)
$\mathrm{MWCNT} / \mathrm{PSF} / \mathrm{CHCl}_{3}$

$\mathrm{MWCNT} / \mathrm{PSF} / \mathrm{CHCl}_{3}$

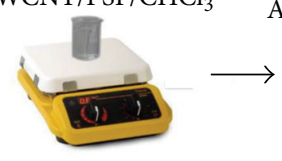

(c) (d)

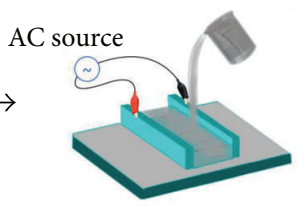

FIGURE 1: Schematic of the solution casting process for the preparation of MWCNT/PSF composites with electric field-aligned MWCNTs.

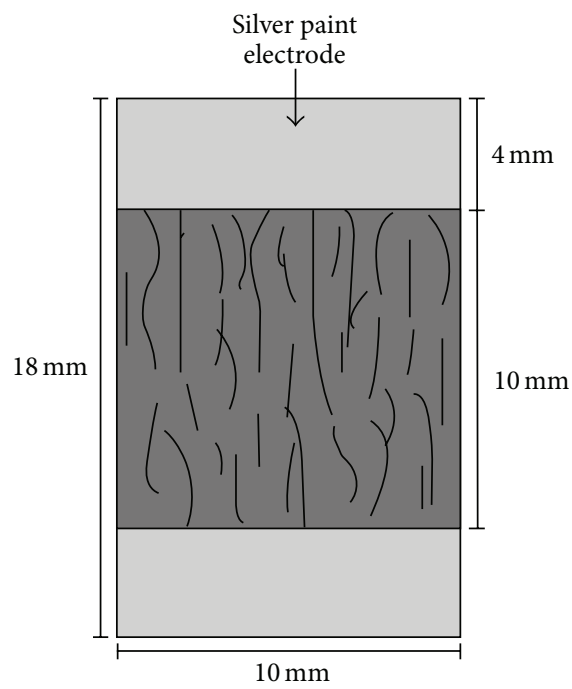

FIGURE 2: MWCNT/PSF specimen for electrical characterization.

evaporated for $24 \mathrm{~h}$ and the viscous solution turned into solid MWCNT/PSF films. Five samples were obtained from each batch. The direct current (DC) electrical conductivity of the samples in the direction of the MWCNT alignment was measured. DC electrical resistance of MWCNT/PSF films was measured at room temperature $\left(25^{\circ} \mathrm{C}\right)$ with a digital multimeter (Agilent 34401A). For the measurement of the electrical resistance, two silver-painted electrodes located at the film edges of the specimen were used. The specimen length was $18 \mathrm{~mm}$ with $4 \mathrm{~mm}$ long electrodes, leaving an effective span $(L)$ of $\sim 10 \mathrm{~mm}$ between the silver electrodes; see Figure 2. The specimen width was $10 \mathrm{~mm}$ and its nominal thickness was $\sim 80 \mu \mathrm{m}$. In order to minimize surface effects in the electrical measurements, silver paint electrodes were painted completely covering the ends of the specimens. A DC voltage of $40 \mathrm{~V}$ was applied between the electrodes and the electrical conductivity $\left(\sigma_{e}\right)$ was calculated using the measured electrical resistance $(R)$ and the specimen dimensions as

$$
\sigma_{e}=\frac{L}{A R}
$$

where $A$ is the cross-sectional area of the specimen.
2.2. Deposition of Cadmium Sulfide by Chemical Bath Deposition. MWCNT/PSF specimens with a surface area of $1 \mathrm{~cm} \times$ $1 \mathrm{~cm}$ were used as substrates for the CdS deposition by CBD. As a first step, the substrates were cleaned following a protocol which includes washing steps with liquid soap and isopropyl alcohol, ultrasonic agitation, distilled water for rinsing, and drying with compressed air. The cleaning process of the substrates was carried out right before the CdS deposition. For the chemical bath preparation, four aqueous solutions were prepared as follows: $200 \mathrm{~mL}$ of $0.50 \mathrm{M}$ potassium hydroxide $(\mathrm{KOH}), 80 \mathrm{~mL}$ of $1.5 \mathrm{M}$ ammonium nitrate $\left(\mathrm{NH}_{4} \mathrm{NO}_{3}\right), 80 \mathrm{~mL}$ of $0.025 \mathrm{M}$ cadmium chloride $\left(\mathrm{CdCl}_{2}\right)$, and $80 \mathrm{~mL}$ of $0.20 \mathrm{M}$ thiourea $\left(\mathrm{CS}\left(\mathrm{NH}_{2}\right)_{2}\right)$. Distilled water was used to dissolve all the reagents. The chemical bath, with a final volume of $440 \mathrm{~mL}$, was prepared by mixing the mentioned solutions. Five substrates were vertically placed in Teflon substrate holders and immersed within the chemical bath. During the magnetic stirring, the bath was heated using a hot plate until reaching $80^{\circ} \mathrm{C}$, which was the temperature selected for the deposition process [45]. When the solution with the potassium hydroxide, cadmium chloride, and ammonium nitrate reaches $80^{\circ} \mathrm{C}$, the thiourea was added as a final step, initiating the process of $\mathrm{CdS}$ formation. Once the thiourea was added to the solution, the chemical bath changed its coloration from transparent to a yellowish tone, indicating the formation of the CdS. The yellowish coloration reflects the optical property of the material and resembles the correspondent wavelength $(512 \mathrm{~nm})$ of the CdS energy band gap $(2.42 \mathrm{eV})$. The growth of $\mathrm{CdS}$ by $\mathrm{CBD}$ is given by the decomposition of the thiourea $\left(\mathrm{CS}\left(\mathrm{NH}_{2}\right)_{2}\right)$ in presence of a cadmium salt in a basic solution with ammonia as complexing agent. The importance of the formation of the tetra-amino-cadmium complex ions, $\left[\mathrm{Cd}\left(\mathrm{NH}_{3}\right)_{4}\right]^{2+}$, is determinant for the liberation of the $\mathrm{Cd}^{2+}$ ions and a further recombination with $\mathrm{S}^{2-}$ ions to produce CdS [46]. The chemical process for the formation of the CdS can be described through the following chemical reactions [46]:

$$
\begin{aligned}
\mathrm{Cd}^{2+}+2 \mathrm{OH}^{-} & \longrightarrow \mathrm{Cd}(\mathrm{OH})_{2} \\
\mathrm{NH}_{4}^{+}+\mathrm{OH}^{-} & \longrightarrow \mathrm{NH}_{3}+\mathrm{H}_{2} \mathrm{O} \\
\mathrm{Cd}(\mathrm{OH})_{2}+4 \mathrm{NH}_{3} & \longrightarrow\left[\mathrm{Cd}\left(\mathrm{NH}_{3}\right)_{4}\right]^{2+}+2 \mathrm{OH}^{-} \\
\mathrm{CS}\left(\mathrm{NH}_{2}\right)_{2}+2 \mathrm{OH}^{-} & \longrightarrow \mathrm{S}^{2-}+\mathrm{CN}_{2} \mathrm{H}_{2}+2 \mathrm{H}_{2} \mathrm{O} \\
{\left[\mathrm{Cd}\left(\mathrm{NH}_{3}\right)_{4}\right]^{2+}+\mathrm{S}^{2-} } & \longrightarrow \mathrm{CdS}(\mathrm{s})+4 \mathrm{NH}_{3}
\end{aligned}
$$

In the CBD technique, deposition of the CdS (metal-chalcogenide) occurs in the surface of the substrates immersed in aqueous solution containing both the metal and the chalcogenide ions. The deposition occurs when the ionic product of the metallic and chalcogenide ions exceeds the solubility product $\mathrm{Ksp}$ (for $\mathrm{CdS}$ at $25^{\circ} \mathrm{C}, \mathrm{Ksp}=10^{-28}$ ) [47]. The ions are chemically attached in the aqueous medium and precipitate onto the surface of the substrate producing the metalchalcogenide film. For the formation of the CdS, OrtegaBorges and Lincot [48] proposed an atom-by-atom growth mechanism in an ammonia-thiourea system through the 
decomposition of adsorbed thiourea molecules due to the formation of an intermediate complex with cadmium hydroxide. In another report, Doña and Herrero proposed a modification of the mechanism of CdS growth through the kinetic study of another intermediate species, the hydroxy-amino complexes [49]. Through the study of the CdS microstructure, films can grow by heterogeneous and/or homogenous precipitation. The CdS deposition in the chemical bath takes place onto the surface of the substrates and at the inner reactor walls (heterogeneous reaction) as well as in the chemical bath (homogeneous reaction). The homogeneous reaction is not desirable due to the formation of colloids, which precipitate as powders and promote the formation of films with low adherence [48]. The substrates were finally taken out after 60 minutes. The $\mathrm{CdS} /$ composite samples were rinsed with distilled water and the deposited CdS of one surface of the substrate was removed using isopropyl alcohol. As a final step, the thickness of the CdS films was measured by a highresolution profilometer (Dektak 8) through a step on the corner of the substrate where the material was carefully removed using isopropyl alcohol. CdS thin films with an average thickness of $475 \mathrm{~nm}$ were obtained from the CBD technique.

\subsection{Characterization of CdS Thin Films}

2.3.1. Optical Properties. It is well known that CdS is a semiconductor with a direct energy band gap $\left(E_{g}\right)$. The absorption coefficient $(\alpha)$ obeys the equation [50]

$$
\alpha=\frac{k}{h v}\left(h v-E_{g}\right)^{1 / 2}
$$

where $k$ is constant, $h$ is the Planck constant, and $v$ is the light frequency. $E_{g}$ value of the CdS film was estimated from the straight line fitted at the absorption edge of the $(\alpha h \nu)^{2}$ versus $h \nu$ plot by extrapolating the linear portion of the graph of the energy axis at $\alpha=0$. Spectrophotometry UV-Vis (Thermo Scientific Evolution 300) was used to evaluate the absorption spectrum of the CdS films in the wavelength range 300$650 \mathrm{~nm}$ and $E_{g}$ value of the films was estimated. Although the MWCNT/PSF composites were fabricated following the same procedure and the morphology of all the samples was similar, it would not be correct to use a single MWCNT/PSF substrate as the one reference (to be subtracted) for the spectrophotometer during all the optical characterization. Thus, in order to adequately capture the optical properties of the CdS films, MWCNT/PSF substrates were labeled and the absorption spectrum of each one was individually measured and registered before the $\mathrm{CdS}$ deposition. Once the $\mathrm{CdS}$ was deposited by CBD, the absorption spectra of the system $\mathrm{CdS} /$ substrate were registered and the absorption spectrum of the corresponding labeled substrate was subtracted as a final step, therefore eliminating the optical contribution of the composite substrate for each individual sample.

2.3.2. Morphology. The morphology of the CdS films was analyzed by AFM and SEM. AFM images of $1 \mu \mathrm{m} \times 1 \mu \mathrm{m}$ (SPM AMBIOS Universal) were obtained from the surface of the CdS films and the average grain size and rms roughness were estimated. The rms roughness was calculated using the WSxM software of "Nanotec Electronica" Company [51]. To calculate the mean grain size, a home-built algorithm implemented in the software "Mathematica" was used. The algorithm transforms the digital image of local heights into a continuous function which represents a "mathematical mold" (a contour map) of the film surface. The lateral grain size is defined as the larger distance between the intersections of the contour map (grain boundaries) and the average grain size of the image is estimated using a maximum and minimum criterion. A detailed explanation of the algorithm can be found elsewhere $[52,53]$. Additionally, SEM images (JEOL JSM-6010LA) were obtained from the samples.

2.3.3. Crystalline Structure. To investigate the crystalline structure and preferential orientation of the CdS films, X-ray diffraction (XRD) profiles were obtained from the samples by two different configurations, the grazing incident angle configuration (Siemens D5000) and the Bragg-Brentano configuration (Bruker D8 Advance).

\section{Results and Discussion}

3.1. Electrical Conductivity of the MWCNT/PSF Substrates. The DC electrical conductivity $\left(\sigma_{e}\right)$ of the MWCNT/PSF samples $(>20)$ obtained from different batches was estimated by measuring the electrical resistance of the samples and using (1). The average $\sigma_{e}$ value was measured as $7.44 \times 10^{-2} \mathrm{~S} / \mathrm{m}$, being such a conductivity value 13 orders of magnitude higher than the conductivity of the pure PSF $\left(\sim 10^{-15} \mathrm{~S} / \mathrm{m}\right)$. The increase of $\sigma_{e}$ in the direction of the MWCNT alignment can be correlated to the formation of interconnected conducting paths spanning the electrodes. As a consequence, the electrons can easily travel through the conducting paths and the electrical conductivity increases in such a direction. In previous reports by our group, the application of electric fields to fabricate aligned MWCNT/PSF composites (technique here used) and the correlation between the morphologies observed at different length scales, from macro- to nanoscale, have been reported and the electrical properties of the composites have been explored $[41,54]$. From these reports, the electric field alignment of MWCNTs can be appreciated at the macroscale by optical images $[41,54]$, at the microscale by SEM images of aligned MWCNT bundles [54], and at the nanoscale, where the alignment of individual MWCNTs was appreciated by TEM images [41]. The results observed here are thus in good agreement with such previous works that report that the orientation of the CNTs within the polymer significantly enhances the value of electrical conductivity $[41,54,55]$. Although the electrical conductivity of the MWCNT/polymer composite is still significantly lower than the conductivity of a metallic layer $\left(\sim 10^{4} \mathrm{~S} / \mathrm{m}\right)$, the notorious increase of such a value due to the presence of the tailored MWCNTs represents an important result towards the fabrication of electrically enhanced polymer composites, and optimized procedures and strategies to reach higher electrical conductivities for composites are object of current investigation. 


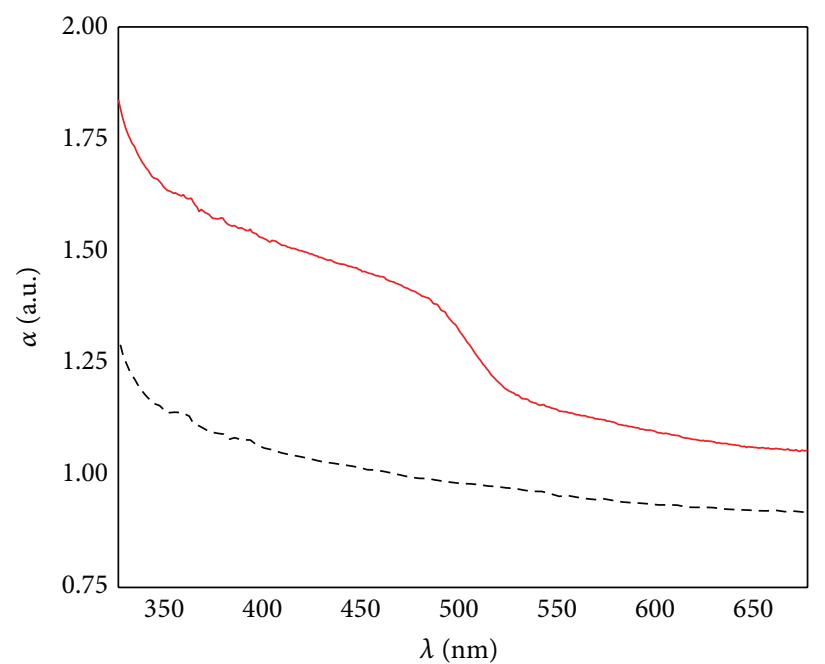

- - - MWCNT/PSF (only substrate)

- CdS/substrate

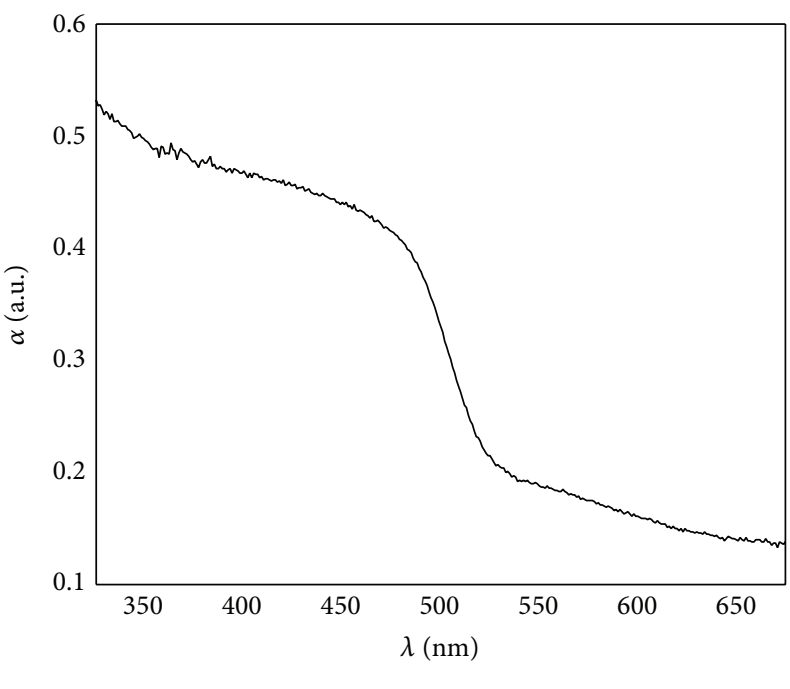

CdS only (substrate subtracted)

(a)

(b)

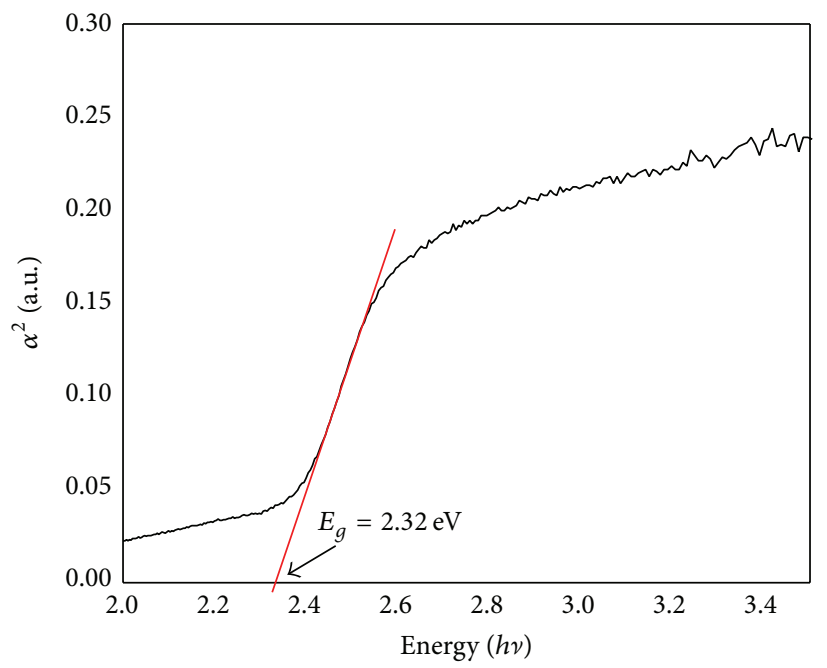

(c)

FIGURE 3: Optical characterization of a representative CdS thin film deposited by CBD. (a) Absorbance spectra of the MWCNT/PSF substrate (dashed line) and of the CdS/substrate system (solid line) as a function of the wavelength, (b) absorbance spectrum of the CdS/film obtained by subtracting the reference spectrum (substrate), and (c) $\alpha^{2}$ versus energy $(h \nu)$ plot obtained from data of Figure 3(b). The straight line in the linear portion of the plot is included for clarification purposes.

3.2. Absorbance Spectrum and Energy Band Gap of the CdS Films. The absorbance spectrum of the CdS films was obtained by UV-Vis spectrophotometry and $E_{g}$ was estimated using (7). Figure 3(a) shows representative plots of the absorption spectra registered from the MWCNT/PSF substrate before the CdS deposition (dashed line) and from the system CdS/substrate (solid line). It can be observed that the intensity of the absorption spectrum of the substrate solely (without CdS film) is lower than the spectrum of the system CdS/substrate, thus allowing the optical characterization of the CdS film. The absorption of the spectrum (reference) was then subtracted from the spectrum of the whole $\mathrm{CdS} /$ substrate system and the resulting spectrum, correspondent to the CdS thin film, is shown in Figure 3(b). It can be observed that a notorious decrease on the absorbance occurs in the wavelength range from $450 \mathrm{~nm}$ to $550 \mathrm{~nm}$. Such a decreasing behavior within the mentioned wavelength range was consistently observed for all the CdS samples. A typical $\alpha^{2}$ versus energy $(h v)$ plot is shown in Figure 3(c). The plot in Figure 3(c) was obtained from the data of the absorbance spectrum in Figure 3(b) and by means of (7), and $E_{g}$ of $2.32 \mathrm{eV}$ was estimated (value of energy when the straight line crosses $\alpha=0$ ). The solid line extrapolating the linear portion of the graph is presented for clarification purposes. Similar process for the optical characterization was applied to all the CdS/composite samples and the average $E_{g}$ 
was calculated as $2.33 \pm 0.04 \mathrm{eV}$. The average value of $E_{g}$ is very similar to $E_{g}$ reported for CdS thin films deposited onto glass at room temperature (2.31-2.34 eV) under similar experimental conditions [56, 57]. Faraj and Ibrahim carried out a comparative study of CdS deposited by thermal evaporation onto a polymeric substrate (polyethylene terephthalate, PET) and onto glass [4]. They found that $E_{g}$ of CdS deposited onto PET was slightly lower $(2.41 \mathrm{eV})$ than $E_{g}$ of the CdS deposited onto glass $(2.43 \mathrm{eV})$. In another report, Lee evaluated the influence of the substrate (different polymers and glass) on the optical properties of CdS films deposited by CBD [32]. He found that the energy band gaps of the samples deposited onto polycarbonate and PET substrates were 2.32 and $2.31 \mathrm{eV}$, respectively, and such a value increased to 2.37 for the CdS deposited onto glass. Author also suggested that the deviation of $E_{g}$ values from the standard bulk value $(2.42 \mathrm{eV})$ can be explained on the basis on the small grain size of the substrates, which could explain the lower average value of $E_{g}$ obtained in this investigation. Moon et al. reported a comparative study of the CdS film properties deposited onto different substrates by RF sputtering [34]. Authors reported that $E_{g}$ values of CdS films deposited onto polycarbonate and PET were not consistent with $E_{g}$ of the CdS deposited onto glass and suggest that such an inconsistency may be associated with the optical properties of the polymer substrates, which partly absorb the light in the high energy range of the visible spectrum. The results obtained here show that the selection of MWCNT/PSF polymeric substrate with a low concentration of MWCNTs does not importantly affect the optical properties of the deposited CdS thin films as compared to the CdS films deposited onto glass.

3.3. Morphology of CdS Films. The rms roughness of the polymeric substrate and the mean grain size and rms roughness of the CdS films were estimated from AFM images by means of the procedure previously described. Figure 4(a) shows a two-dimensional micrograph of a scanned region of $1 \mu \mathrm{m}$ $\times 1 \mu \mathrm{m}$ of the MWCNT/PSF polymeric substrate. As can be appreciated, the roughness is very low and a mean rms roughness value of $0.285 \mathrm{~nm}$ is estimated, being this value in the order of the values typically observed on glass substrates $(\sim 0.35 \mathrm{~nm})$ [58]. Figure $4(\mathrm{~b})$ presents a two-dimensional micrograph of a scanned region of $1 \mu \mathrm{m} \times 1 \mu \mathrm{m}$ where the grains and their boundaries can be appreciated. A markedly different morphology with respect to the morphology of the substrate in Figure 4(a) is observed in Figure 4(b), due to the formation of the CdS thin film.

As previously mentioned, a home-built algorithm implemented in the commercial software "Mathematica" was used to calculate the average grain size of the sample. The algorithm uses the difference of intensities of the image to assign the grain limits and then to calculate the required parameters. Figure 4(c) shows an example of the grain boundaries of the AFM micrograph in Figure 4(b) traced by the algorithm. The mean grain size and rms roughness of the CdS films deposited onto the polymeric substrate were calculated as $271 \mathrm{~nm}$ and $11 \mathrm{~nm}$, respectively. For CdS film deposited onto a glass substrate by similar experimental conditions, the mean grain size and rms roughness were estimated as $269 \mathrm{~nm}$ and $21 \mathrm{~nm}$, respectively [56]. SEM image of the CdS film is presented in Figure 5. Some grains with size larger than the mean size can be appreciated but in general a uniform morphology of the surface can be observed, corresponding to the surface morphology observed by AFM on a smaller region; see Figure 4(b). The uniform morphology of the surface can be correlated with a good formation and adhesion of the CdS thin film onto the polymeric substrate. These results confirm that the morphological characteristics of the CdS films are very similar to those of the CdS deposited onto glass, suggesting that the proposed polymeric composite represents a suitable option to be used as a substrate for CdS films.

3.4. Crystalline Structure. XRD profiles of CdS films deposited onto MWCNT/PSF substrates in different experiments were obtained by the grazing incident angle and BraggBrentano configurations in order to evaluate the crystalline structure and preferential orientation of the CdS films and the reproducibility of the deposition process. The XRD profiles of the composite substrates solely (without CdS film) were also obtained from the two configurations. Figure 6(a) shows a representative XRD profile obtained by the grazing angle configuration. The XRD spectra confirm the formation of CdS in a face-centered cubic (fcc) crystalline structure "Hawleyite" with (111) as the preferential orientation, as can be noticed from the presence of the main peak at $2 \theta=26.54^{\circ}$. Secondary peaks of the cubic structure at $44.02^{\circ}$ and $52.14^{\circ}$ were also detected. A wide peak is observed around $2 \theta=18^{\circ}$ which corresponds to the composition of the polymeric substrate. A peak at $29.4^{\circ}$ (marked with " $*$ " in Figure 6(a)) was also noticed; such a peak corresponds to the "fixing putty" used to fix the sample to the sample-holder on the diffractometer. Figure 6(b) shows a representative XRD profile by the BraggBrentano configuration. The main peak at $26.54^{\circ}$ was again detected, confirming the cubic structure and preferential orientation of the CdS films. No peak was observed at $29.4^{\circ}$ as no "fixing putty" was required for the Bragg-Brentano configuration. The observed CdS crystalline structure and preferential orientation are consistent with previous reports of CdS deposited onto glass [46, 56-59]. Also, it has been reported that fcc structure is the most stable structure for CdS films obtained by means of low-temperature techniques (such as the $\mathrm{CBD}$ ) while the hexagonal structure (Greenockite) is the most stable one for high-temperature techniques (e.g., sputtering or closed space sublimation) $[29,34,60]$.

\section{Conclusions}

CdS thin films were deposited by CBD onto flexible polymeric substrates. AC electric field was applied during the fabrication of the polymeric composite substrates to induce preferential alignment of the MWCNTs within the polymer during the fabrication process. After the solvent evaporation, solid MWCNT/polysulfone composites with MWCNTs aligned in the electric field direction were obtained, with an electrical conductivity 13 orders of magnitude higher than the conductivity of the pure polymer. CdS thin films 


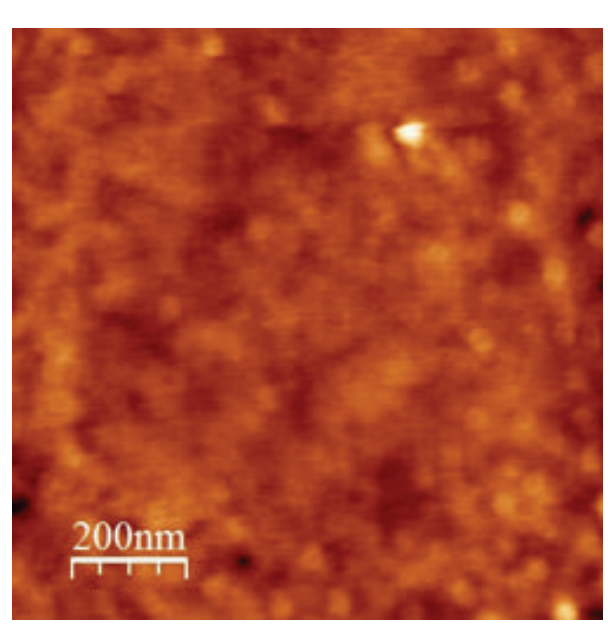

(a)

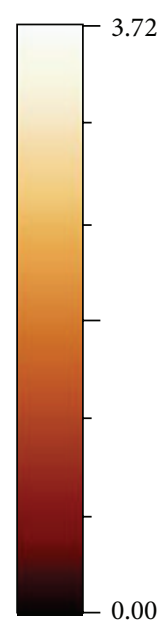

0.00

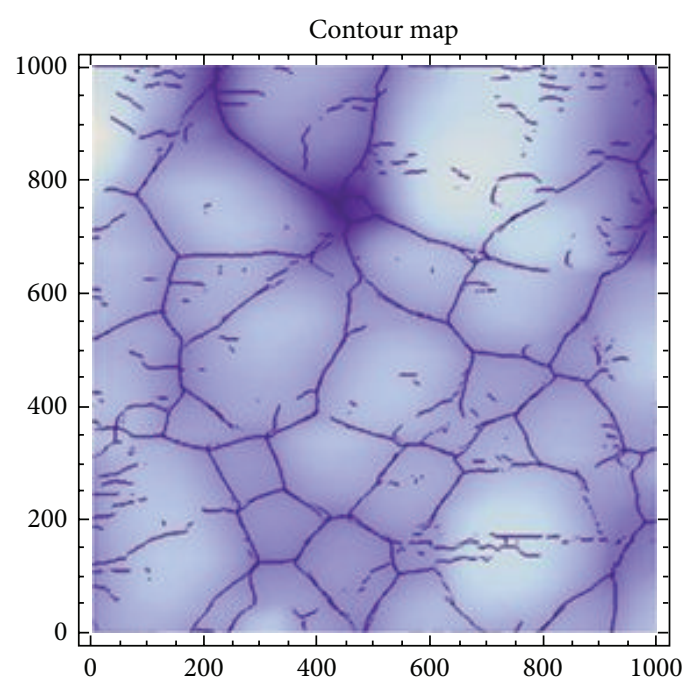

(c)

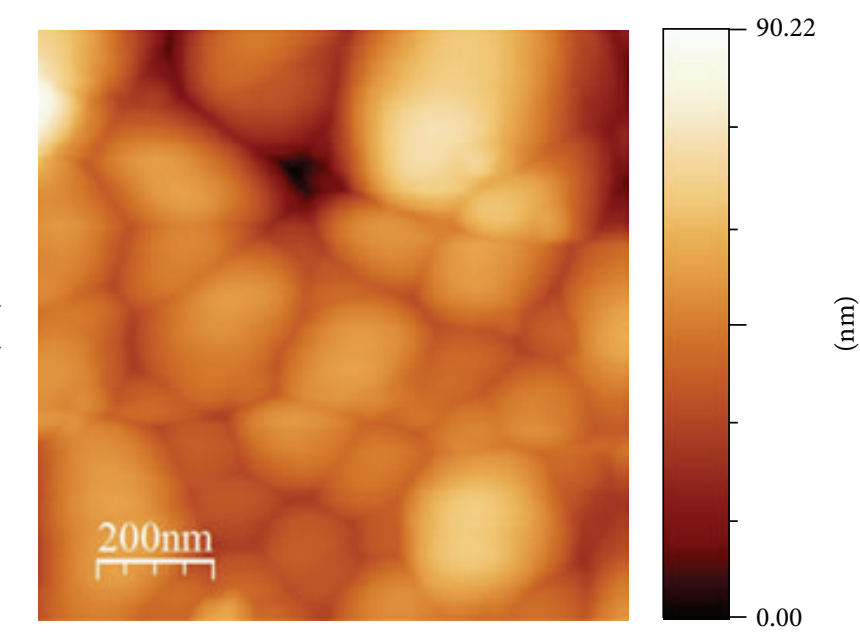

(b)

Figure 4: AFM images of the CdS film deposited onto MWCNT/PSF substrate. (a) Two-dimensional image of $1 \mu \mathrm{m} \times 1 \mu \mathrm{m}$ of the MWCNT/PSF polymeric substrate (without film), (b) two-dimensional image of $1 \mu \mathrm{m} \times 1 \mu \mathrm{m}$ of the CdS film deposited by CBD, and (c) contour map with the grain boundaries traced by the home-built algorithm implemented in "Mathematica" to calculate the mean grain size of the CdS.

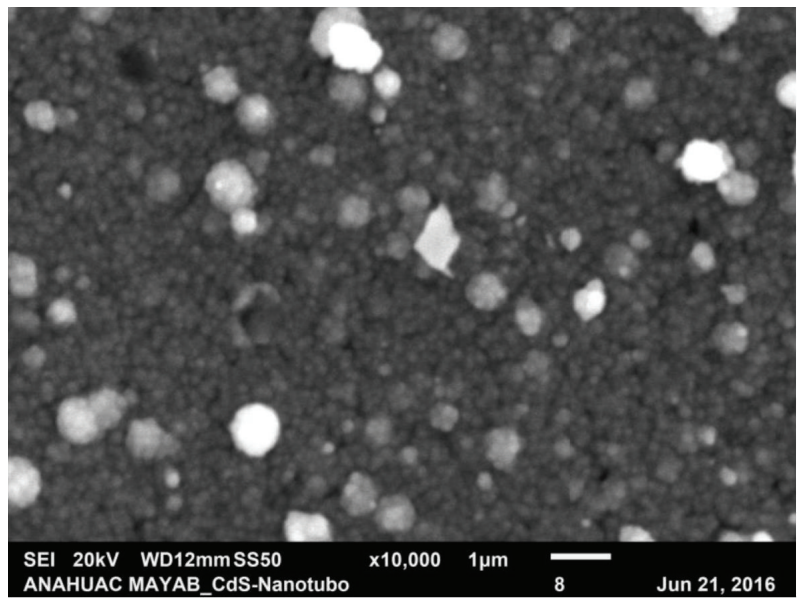

Figure 5: SEM image of the CdS film deposited by CBD onto MWCNT/PSF polymeric substrate. were deposited onto the MWCNT/PSF substrates by CBD and the optical, morphological, and structural properties were evaluated. CdS thin films with an average thickness of $475 \mathrm{~nm}$, good adherence, and transparency were successfully obtained by the proposed procedure. The average energy band gap was measured as $2.33 \mathrm{eV}$, a similar value to that of the CdS deposited onto glass. The mean grain size $(271 \mathrm{~nm})$ and $\mathrm{rms}$ roughness $(11 \mathrm{~nm})$ were found to be very similar to the values reported for $\mathrm{CdS}$ deposited onto glass by similar experimental conditions. XRD patterns measured by two different configurations confirm the formation of $\mathrm{CdS}$ in Hawleyite (fcc) crystalline structure with (111) as preferential orientation, which is in agreement with the most stable structure for CdS grown by low-temperature techniques, such as the CBD. From the observed results it can be concluded that the electrically enhanced MWCNT/PSF flexible composites are suitable substrates for the deposition 


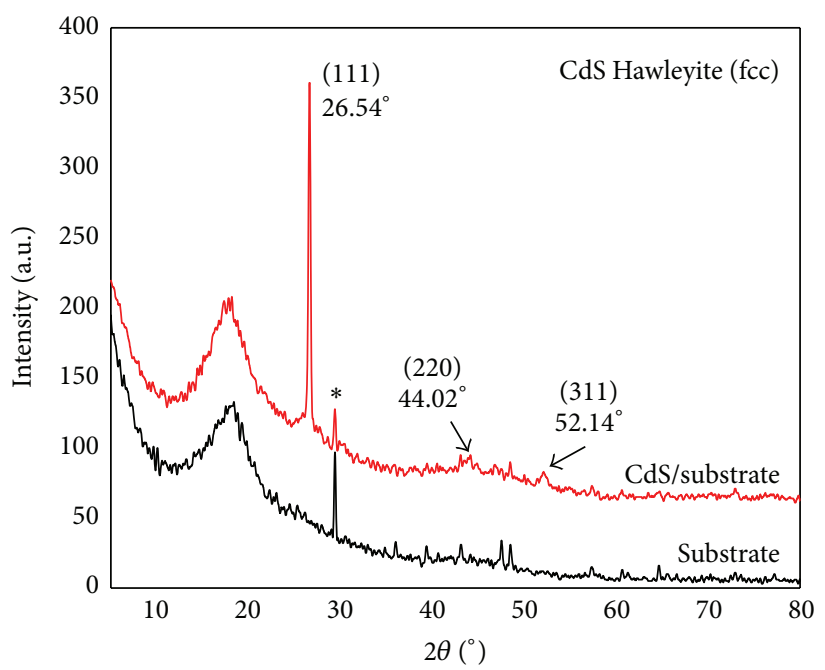

(a)

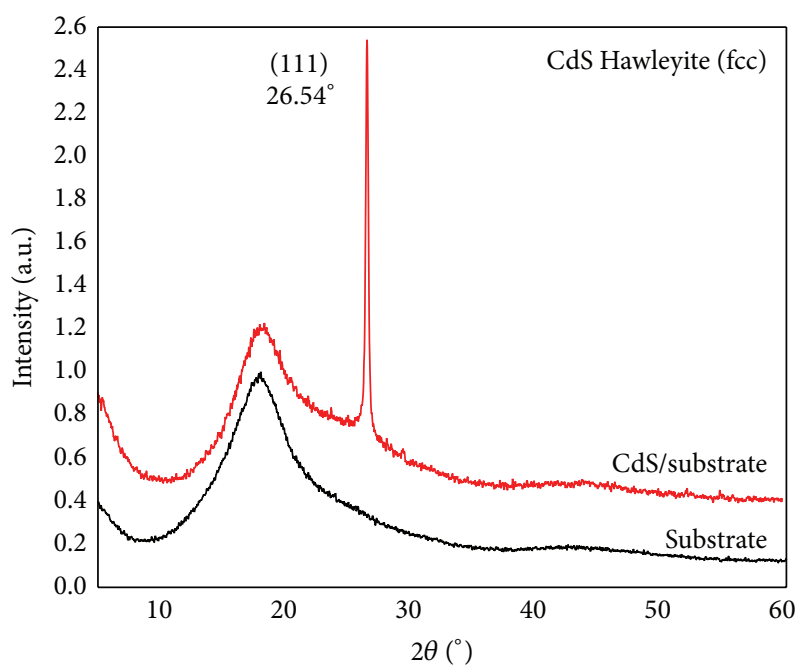

(b)

FIGURE 6: XRD profiles of CdS films deposited onto MWCNT/PSF composite substrates by two different configurations: (a) grazing incident angle configuration and (b) Bragg-Brentano configuration. The XRD profile of the composite substrate solely (without CdS film) is also presented on each plot.

of CdS by CBD, representing an important step towards the development of more versatile and functional materials for photovoltaic applications.

\section{Competing Interests}

The authors declare that there are no competing interests regarding the publication of this paper.

\section{Acknowledgments}

This work was supported by the "Fondo Sectorial de Investigación para la Educación" through the SEP-CONACYT Grant no. 235905 (A. I. Oliva-Avilés) and by the Projects no. 251932 and no. 235637 (CONACYT). The authors also thank the technical assistance of Daniel Aguilar, Emilio Corona, Mauricio Romero, Wilian Cauich (CINVESTAV), Rubén Domínguez, Yazmín Sabido (Universidad Anáhuac Mayab), and Francis Avilés (CICY).

\section{References}

[1] R. Tenne, V. M. Nabutovsky, E. Lifshitz, and A. F. Francis, "Unusual photoluminescence of porous CdS (CdSe) crystals," Solid State Communications, vol. 82, no. 9, pp. 651-654, 1992.

[2] V. Ruxandra and S. Antohe, "The effect of the electron irradiation on the electrical properties of thin polycrystalline CdS layers," Journal of Applied Physics, vol. 84, no. 2, pp. 727-733, 1998.

[3] B. Su and K. L. Choy, "Electrostatic assisted aerosol jet deposition of CdS, CdSe and ZnS thin films," Thin Solid Films, vol. 361, pp. 102-106, 2000.

[4] M. G. Faraj and K. Ibrahim, "Comparison of cadmium sulfide thin films deposited on glass and polyethylene terephthalate substrates with thermal evaporation for solar cell applications,"
Journal of Materials Science: Materials in Electronics, vol. 23, no. 6, pp. 1219-1223, 2012.

[5] X. Wu, J. C. Keane, R. G. Dhere et al., "16.5\%-Efficient CdS/CdTe polycrystalline thin-film solar cells," in Proceedings of the 17th European Photovoltaic Solar Energy Conference (EU PVSEC '01), p. 995, 2001.

[6] K. Ramanathan, M. A. Contreras, C. L. Perkins et al., "Properties of $19.2 \%$ efficiency $\mathrm{ZnO} / \mathrm{CdS} / \mathrm{CuInGaSe}_{2}$ thin-film solar cells," Progress in Photovoltaics: Research and Applications, vol. 11, no. 4, pp. 225-230, 2003.

[7] K. D. Dobson, I. Visoly-Fisher, G. Hodes, and D. Cahen, "Stability of CdTe/CdS thin-film solar cells," Solar Energy Materials and Solar Cells, vol. 62, no. 3, pp. 295-325, 2000.

[8] R. L. N. Chandrakanthi and M. A. Careem, "Preparation and characterization of $\mathrm{CdS}$ and $\mathrm{Cu} 2 \mathrm{~S}$ nanoparticle/polyaniline composite films," Thin Solid Films, vol. 417, no. 1-2, pp. 51-56, 2002.

[9] V. K. Kapur, B. M. Basol, and E. S. Tseng, "Low cost methods for the production of semiconductor films for $\mathrm{CuInSe}_{2} / \mathrm{CdS}$ solar cells," Solar Cells, vol. 21, no. 1-4, pp. 65-72, 1987.

[10] M. Purica, E. Budianu, E. Rusu, and P. Arabadji, "Electrical properties of the CdS/InP heterostructures for photovoltaic applications," Thin Solid Films, vol. 511-512, pp. 468-472, 2006.

[11] O. A. Ileperuma, C. Vithana, K. Premaratne, S. N. Akuranthilaka, S. M. McGregor, and I. M. Dharmadasa, "Comparison of CdS thin films prepared by different techniques for applications in solar cells as window materials," Journal of Materials Science: Materials in Electronics, vol. 9, no. 5, pp. 367-372, 1998.

[12] A. E. Rakhshani and A. S. Al-Azab, "Characterization of CdS films prepared by chemical-bath deposition," Journal of Physics Condensed Matter, vol. 12, no. 40, pp. 8745-8755, 2000.

[13] S. Mathew, P. S. Mukerjee, and K. P. Vijayakumar, "Optical and surface properties of spray-pyrolysed CdS thin films," Thin Solid Films, vol. 254, no. 1-2, pp. 278-284, 1995.

[14] X. L. Tong, D. S. Jiang, Y. Li, Z. M. Liu, and M. Z. Luo, "Femtosecond pulsed laser deposition of CdS thin films onto quartz 
substrates," Physica Status Solidi (A), vol. 203, no. 8, pp. 19921998, 2006.

[15] P. Boieriu, R. Sporken, Y. Xin, N. D. Browning, and S. Sivananthan, "Wurtzite CdS on CdTe grown by molecular beam epitaxy," Journal of Electronic Materials, vol. 29, no. 6, pp. 718$722,2000$.

[16] B. R. Sankapal, R. S. Mane, and C. D. Lokhande, "Deposition of CdS thin films by the Successive Ionic Layer Adsorption and Reaction (SILAR) method," Materials Research Bulletin, vol. 35, no. 2, pp. 177-184, 2000.

[17] D. Patidar, R. Sharma, N. Jain, T. P. Sharma, and N. S. Saxena, "Optical properties of CdS sintered film," Bulletin of Materials Science, vol. 29, no. 1, pp. 21-24, 2006.

[18] Muneeb-ur-Rehman, A. K. S. Aqili, M. Shafique, Z. Ali, A. Maqsood, and A. Kazmi, "Properties of silver-doped CdS thin films prepared by closed space sublimation (CSS) techniques," Journal of Materials Science Letters, vol. 22, no. 2, pp. 127-129, 2003.

[19] I. Mártil de la Plaza, G. González-Díaz, F. Sánchez-Quesada, and M. Rodríguez-Vidal, "Structural and optical properties of r.f.-sputtered CdS thin films," Thin Solid Films, vol. 120, no. 1, pp. 31-36, 1984.

[20] M. Tsuji, T. Aramoto, H. Ohyama, T. Hibino, and K. Omura, "Characterization of CdS thin-film in high efficient CdS/CdTe solar cells," Japanese Journal of Applied Physics, vol. 39, no. 7, pp. 3902-3906, 2000.

[21] O. Vigil-Galán, J. Vidal-Larramendi, A. Escamilla-Esquivel et al., "Physical properties of CdS thin films grown by pulsed laser ablation on conducting substrates: effect of the thermal treatment," Physica Status Solidi A: Applications and Materials Science, vol. 203, no. 8, pp. 2018-2023, 2006.

[22] S. A. Mahmoud, A. A. Ibrahim, and A. S. Riad, "Physical properties of thermal coating CdS thin films using a modified evaporation source," Thin Solid Films, vol. 372, no. 1, pp. 144-148, 2000.

[23] J. Herrero, M. T. Gutiérrez, C. Guillén et al., "Photovoltaic windows by chemical bath deposition," Thin Solid Films, vol. 361, pp. 28-33, 2000.

[24] J. Britt and C. Ferekides, "Thin-film CdS/CdTe solar cell with 15.8\% efficiency," Applied Physics Letters, vol. 62, no. 22, pp. 2851-2852, 1993.

[25] B. Ullrich and R. Schroeder, "Green emission and bandgap narrowing due to two-photon excitation in thin film CdS formed by spray pyrolysis," Semiconductor Science and Technology, vol. 16, no. 8, pp. L37-L39, 2001.

[26] N. Romeo, A. Bosio, R. Tedeschi, and V. Caneveri, "Growth of polycrystalline CdS and CdTe thin layers for high efficiency thin film solar cells," Materials Chemistry and Physics, vol. 66, no. 2, pp. 201-206, 2000.

[27] X. L. Tong, D. S. Jiang, Y. Li, Z. M. Liu, and M. Z. Luo, “The influence of the silicon substrate temperature on structural and optical properties of thin-film cadmium sulfide formed with femtosecond laser deposition," Physica B: Condensed Matter, vol. 382, no. 1-2, pp. 105-109, 2006.

[28] K. P. Acharya, A. Erlacher, and B. Ullrich, "Optoelectronic properties of $\mathrm{ZnTe} / \mathrm{Si}$ heterostructures formed by nanosecond laser deposition at different Nd:YAG laser lines," Thin Solid Films, vol. 515, no. 7-8, pp. 4066-4069, 2007.

[29] K. P. Acharya, J. R. Skuza, R. A. Lukaszew, C. Liyanage, and B. Ullrich, "CdS thin films formed on flexible plastic substrates by pulsed-laser deposition," Journal of Physics Condensed Matter, vol. 19, no. 19, Article ID 196221, 2007.
[30] X. Mathew, G. W. Thompson, V. P. Singh et al., "Development of CdTe thin films on flexible substrates-a review," Solar Energy Materials and Solar Cells, vol. 76, no. 3, pp. 293-303, 2003.

[31] X. Mathew, J. Pantoja Enriquez, A. Romeo, and A. N. Tiwari, "CdTe/CdS solar cells on flexible substrates," Solar Energy, vol. 77, no. 6, pp. 831-838, 2004.

[32] J.-H. Lee, "Influence of substrates on the structural and optical properties of chemically deposited CdS films," Thin Solid Films, vol. 515, no. 15, pp. 6089-6093, 2007.

[33] J.-H. Lee, "Structural and optical properties of CdS thin films on organic substrates for flexible solar cell applications," Journal of Electroceramics, vol. 17, no. 2-4, pp. 1103-1108, 2006.

[34] B.-S. Moon, J.-H. Lee, and H. Jung, "Comparative studies of the properties of CdS films deposited on different substrates by R.F. sputtering," Thin Solid Films, vol. 511-512, pp. 299-303, 2006.

[35] D. Lim, J.-H. Lee, and W. Song, "Improvement of the characteristics of chemical bath deposition-cadmium sulfide films deposited on an $\mathrm{O}_{2}$ plasma-treated polyethylene terephthalate substrate," Thin Solid Films, vol. 546, pp. 317-320, 2013.

[36] E. T. Thostenson, Z. Ren, and T.-W. Chou, "Advances in the science and technology of carbon nanotubes and their composites: a review," Composites Science and Technology, vol. 61, no. 13, pp. 1899-1912, 2001.

[37] T.-W. Chow, L. Gao, E. T. Thostenson, Z. Zhang, and J.-H. Byun, "An assessment of the science and technology of carbon nanotube-based fibers and composites," Composites Science and Technology, vol. 70, no. 1, pp. 1-19, 2010.

[38] L. Dai, D. W. Chang, J.-B. Baek, and W. Lu, "Carbon nanomaterials for advanced energy conversion and storage," Small, vol. 8, no. 8, pp. 1130-1166, 2012.

[39] C. Park, J. Wilkinson, S. Banda et al., "Aligned single-wall carbon nanotube polymer composites using an electric field," Journal of Polymer Science, Part B: Polymer Physics, vol. 44, no. 12, pp. 1751-1762, 2006.

[40] Y. Zhu, C. Ma, W. Zhang, R. Zhang, N. Koratkar, and J. Liang, "Alignment of multiwalled carbon nanotubes in bulk epoxy composites via electric field," Journal of Applied Physics, vol. 105, no. 5, p. 054319, 2009.

[41] A. I. Oliva-Avilés, F. Avilés, and V. Sosa, "Electrical and piezoresistive properties of multi-walled carbon nanotube/polymer composite films aligned by an electric field," Carbon, vol. 49, no. 9, pp. 2989-2997, 2011.

[42] Solvay Advanced Polymers, Alpharetta, Ga, USA, http://www .solvay.com/.

[43] Bayer Material Science, Leverkusen, Germany, http://www.covestro.com/.

[44] F. Avilés, A. Ponce, J. V. Cauich-Rodríguez, and G. T. Martínez, "TEM examination of MWCNTs oxidized by mild experimental conditions," Fullerenes, Nanotubes and Carbon Nanostructures, vol. 20, no. 1, pp. 49-55, 2012.

[45] A. I. Oliva, R. Castro-Rodríguez, O. Solís-Canto, V. Sosa, P. Quintana, and J. L. Peña, "Comparison of properties of CdS thin films grown by two techniques," Applied Surface Science, vol. 205, no. 1-4, pp. 56-64, 2003.

[46] A. I. Oliva-Avilés, R. Patiño, and A. I. Oliva, "CdS films deposited by chemical bath under rotation," Applied Surface Science, vol. 256, no. 20, pp. 6090-6095, 2010.

[47] G. Hodes, Chemical Solution Deposition of Semiconductor Films, Marcel Dekker, New York, NY, USA, 2002. 
[48] R. Ortega-Borges and D. Lincot, "Mechanism of chemical bath deposition of cadmium sulfide thin films in the ammoniathiourea system," Journal of the Electrochemical Society, vol. 140, no. 12, pp. 3464-3473, 1993.

[49] J. M. Doña and J. Herrero, "Chemical bath deposition of CdS thin films: an approach to the chemical mechanism through study of the film microstructure," Journal of the Electrochemical Society, vol. 144, no. 11, pp. 4081-4091, 1997.

[50] J. Tauc, Amorphous and Liquid Semiconductors, Plenum Press, New York, NY, USA, 1974.

[51] I. Horcas, R. Fernandez, J. M. Gomez-Rodriguez, J. Colchero, J. Gomez-Herrero, and A. M. Baro, "WSXM: a software for scanning probe microscopy and a tool for nanotechnology," Review of Scientific Instruments, vol. 78, Article ID 013705, 2007.

[52] G. M. Alonzo-Medina, A. González-González, J. L. Sacedón, A. I. Oliva, and E. Vasco, "Local slope evolution during thermal annealing of polycrystalline Au films," Journal of Physics D: Applied Physics, vol. 45, no. 43, Article ID 435301, 2012.

[53] A. González-González, J. L. Sacedón, C. Polop, E. RodríguezCaas, J. A. Aznárez, and E. Vasco, "Surface slope distribution with mathematical molding on $\mathrm{Au}(111)$ thin film growth," Journal of Vacuum Science and Technology A: Vacuum, Surfaces and Films, vol. 27, no. 4, pp. 1012-1016, 2009.

[54] A. I. Oliva-Avilés, F. Avilés, V. Sosa, A. I. Oliva, and F. Gamboa, "Dynamics of carbon nanotube alignment by electric fields," Nanotechnology, vol. 23, no. 46, Article ID 465710, 2012.

[55] T. C. Theodosiou and D. A. Saravanos, "Numerical investigation of mechanisms affecting the piezoresistive properties of CNTdoped polymers using multi-scale models," Composites Science and Technology, vol. 70, no. 9, pp. 1312-1320, 2010.

[56] S. Tec-Yam, R. Patiño, and A. I. Oliva, "Chemical bath deposition of CdS films on different substrate orientations," Current Applied Physics, vol. 11, no. 3, pp. 914-920, 2011.

[57] M. Aguilar, A. I. Oliva, P. Quintana, and J. L. Peña, "Dynamic phenomena in the surface of gold thin films: macroscopic surface rearrangements," Surface Science, vol. 380, no. 1, pp. 91-99, 1997.

[58] A. I. Oliva, R. Castro-Rodríguez, O. Ceh, P. Bartolo-Pérez, F. Caballero-Briones, and V. Sosa, "First stages of growth of CdS films on different substrates," Applied Surface Science, vol. 148, no. 1, pp. 42-49, 1999.

[59] R. Castro-Rodríguez, A. I. Oliva, V. Sosa, F. Caballero-Briones, and J. L. Peña, "Effect of indium tin oxide substrate roughness on the morphology, structural and optical properties of CdS thin films," Applied Surface Science, vol. 161, no. 3, pp. 340-346, 2000.

[60] A. I. Oliva, O. Solís-Canto, R. Castro-Rodríguez, and P. Quintana, "Formation of the band gap energy on CdS thin films growth by two different techniques," Thin Solid Films, vol. 391, no. 1 , pp. $28-35,2001$. 

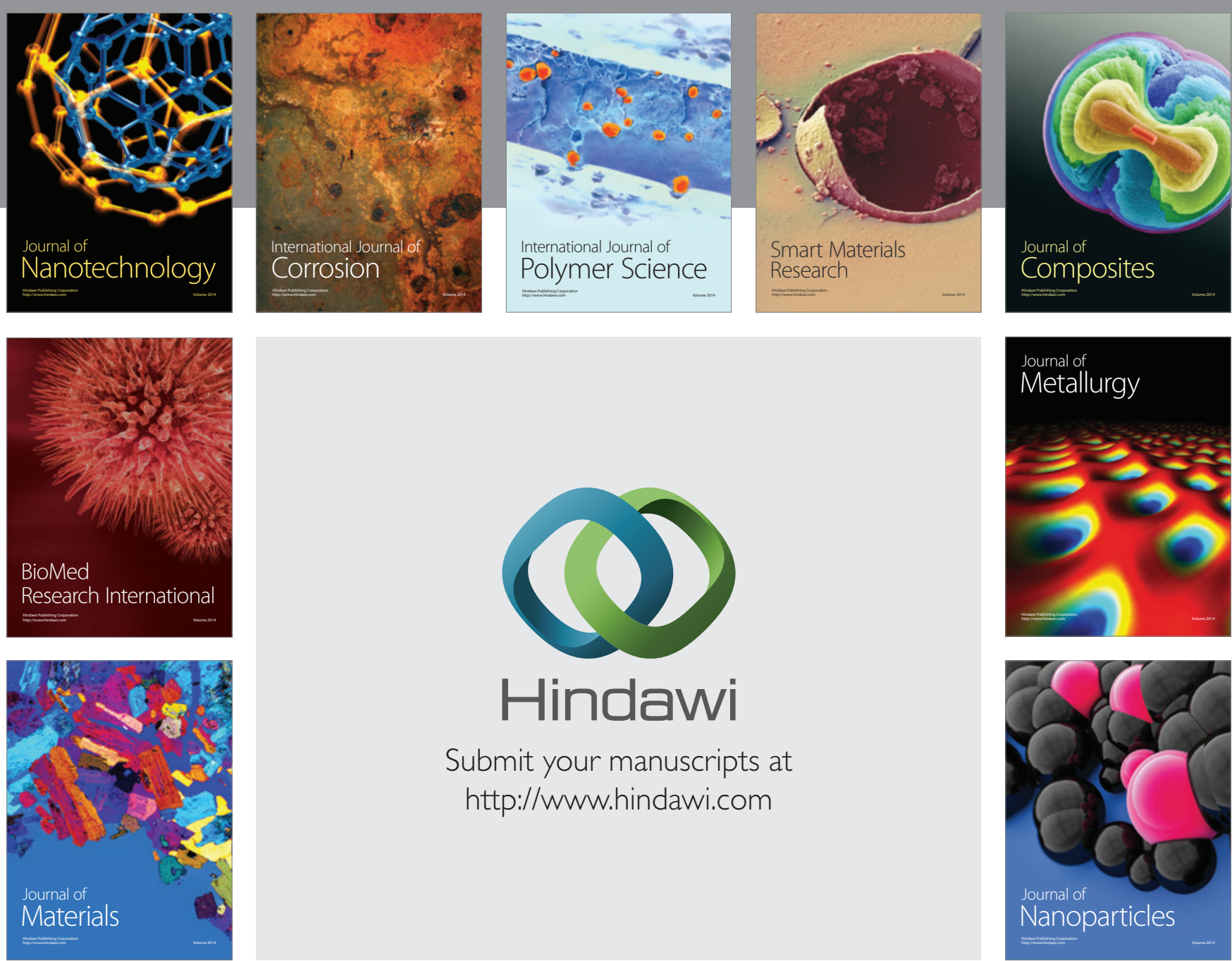

\section{Hindawi}

Submit your manuscripts at

http://www.hindawi.com

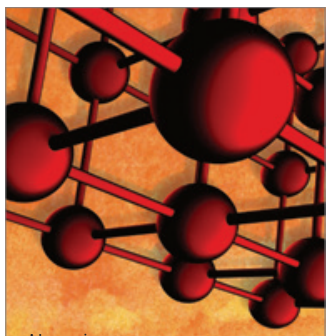

Materials Science and Engineering
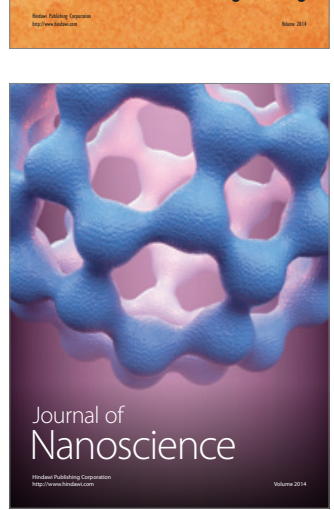
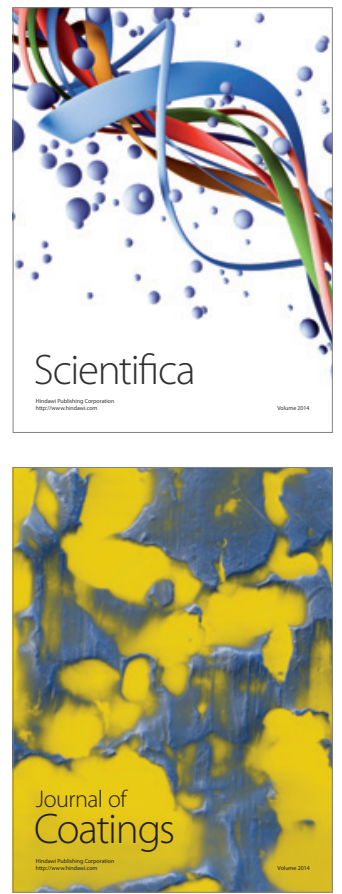
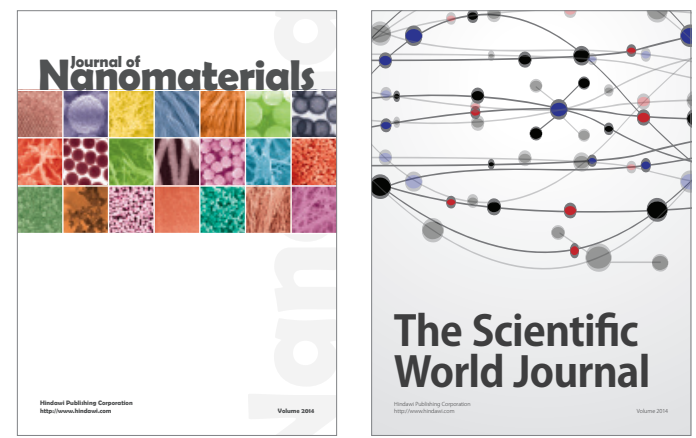

The Scientific World Journal
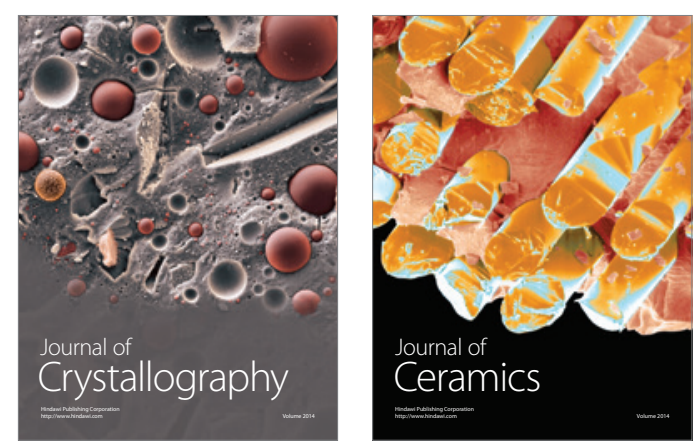
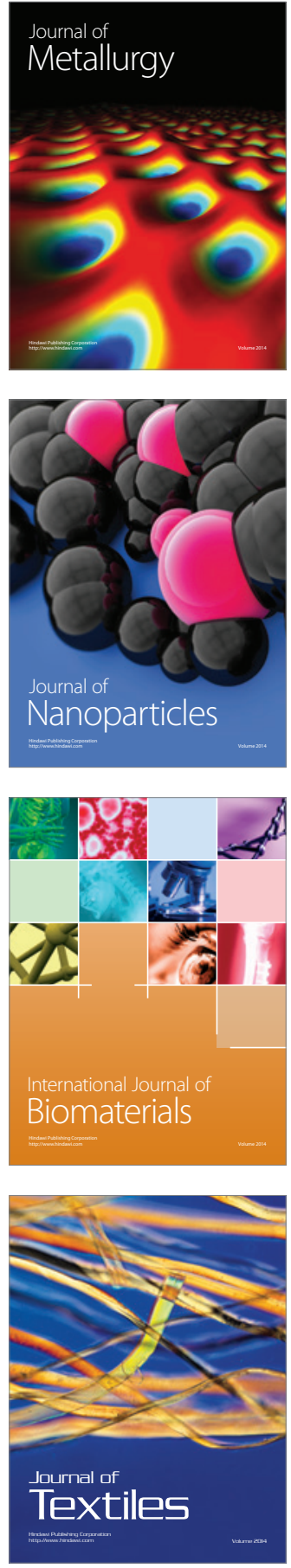